

\title{
Aivold $=$
}

(ISSN 0890-0604)

\section{EDITOR}

\author{
William P. Birmingham \\ University of Michigan
}

\section{EDITORIAL BOARD}

Alice M. Agogino, University of California, Berkeley, CA David C. Brown, Worcester Polytechnic Institute, Worcester, MA Per Christiansson, Lund University, Sweden

John R. Dixon, University of Massachusetts, Amherst, MA

Boi Faltings, Federal Institute of Technology, Lausanne, Switzerland

S. J. Fenves, Carnegie Mellon University, Pittsburgh, PA

Donal Finn, Hitachi Ltd., Dublin, Ireland

Patrick Fitzhorn, Colorado State University, Fort Collins, CO

Mark S. Fox, University of Toronto, Ontario, Canada

John S. Gero, University of Sydney, Australia

Ashok K. Goel, Georgia Institute of Technology, Atlanta, GA

Roderick A. Grupen, University of Massachusetts, Amherst, MA

Mark Klein, Pennsylvania State University, University Park, PA

John C. Kunz, Stanford University, Stanford, CA

Jean-Claude Latombe, Stanford University, Stanford, CA

Raymond E. Levitt, Stanford University, Stanford, CA

Mary Lou Maher, University of Sydney, Australia

\section{John McDermott, Digital Equipment Corporation} Marlborough, $M A$

Sanjay Mittal, Catalogics Software Corporation, Milpitas, CA

Wolfgang Nejdl, University of Hannover, Germany

Panos Papalambros, University of Michigan, Ann Arbor, MI

H. Van Dyke Parunak, Industrial Technology Institute, Ann Arbor, MI

Daniel R. Rehak, Carnegie Mellon University, Pittsburgh, PA

Warren Seering, Massachusetts Institute of Technology, Cambridge, $M A$

Ian Smith, Federal Institute of Technology, Lausanne, Switzerland

Tim Smithers, Universidad del Pais Vasco, Pais Vasco, Spain

Iris D. Tommelein, University of Michigan, Ann Arbor, MI

David G. Ullman, Oregon State University, Corvallis, $O R$

Manjula Waldron, Ohio State University, Columbus, $O H$

Arthur W. Westerberg, Carnegie Mellon University, Pittsburgh, PA

\section{EDITOR EMERITUS (1986-1996)}

Clive L. Dym, Harvey Mudd College

\begin{abstract}
AIEDAM: Artificial Intelligence for Engineering Design, Analysis and Manufacturing is a journal intended to reach two audiences: engineers and designers who see AI technologies as powerful means for solving difficult engineering problems; and researchers in AI and computer science who are interested in applications of $\mathrm{AI}$ and in the theoretical issues that arise from such applications. The journal publishes original articles that develop new and interesting applications based on the most up-to-date research in all branches and phases of engineering, including analysis, synthesis and design; manufacturing and assembly; and concurrent engineering. Specifically, the journal is interested in the use of AI in planning, design, analysis, simulation, spatial reasoning and graphics, manufacturing, assembly, process planning, scheduling, numerical analysis, and optimization. Areas of special interest include:
\end{abstract}

- knowledge-based (expert) systems for engineering, including knowledge acquisition and representation, control, and system architectures

- theoretical work on the modeling of engineering problem-solving and design processes

AIEDAM is also interested in original and serious applications of state-of-the-art knowledge-based techniques to important engineering problems (termed practicum papers). In addition to the rapid publication and dissemination of unsolicited research papers, AIEDAM is committed to producing special issues on topics that are viewed as both important and timely. AIEDAM is indexed in Compendex Plus, SciSearch, Research Alert, and CompuMath Citation Index.

Editorial Office: William P. Birmingham, Editor, AIEDAM: Artificial Intelligence for Engineering Design, Analysis and Manufacturing, Artificial Intelligence Laboratory, Department of Electrical Engineering and Computer Science, The University of Michigan, 128 ATL Building, 1101 Beal Avenue, Ann Arbor, MI, 48109-2110, USA. Telephone: (313) 936-1590. Fax: (313) 763-1260. E-mail: wpb@eecs.umich.edu.

Publishing, Subscription and Advertising Offices: Cambridge University Press, 40 West 20th Street, New York, NY 10011, USA; and (outside the US and Canada) Cambridge University Press, The Edinburgh Building, Shaftesbury Road, Cambridge CB2 2RU, England.

AIEDAM is published in January, April, June, September, and November. Annual institutional subscription rates: US $\$ 224.00$ in the US, Canada, and Mexico; UK $£ 130.00$ + VAT elsewhere. Individual rates: US $\$ 98.00$ in the US, Canada, and Mexico; UK $£ 60.00+$ VAT elsewhere. Single part rates: US $\$ 49.00$ in the US, Canada, and Mexico; UK $\$ 29.00+$ VAT elsewhere. Prices include postage and insurance.

\section{Copyright @ 1997 Cambridge University Press}

Information on AIEDAM and all other Cambridge journals is available via http://www.cup.org/ in North America and in the UK via http:/www.cup.cam.ac.uk/.

All rights reserved. No part of this publication may be reproduced, in any form or by any means, electronic, photocopying or otherwise, without permission in writing from Cambridge University Press. Photocopying information for users in the U.S.A.: The Item-Fee Code for this publication (0890-0604/97 $\$ 11.00+.10)$ indicates that copying for internal or personal used beyond that permitted by Sec. 107 or 108 of the U.S. Copyright Law is authorized for users duly registered with the Copyright Clearance Center (CCC) Transaction Reporting Service, provided that the appropriate remittance per article is paid directly to: CCC, 222 Rosewood Drive, Danvers, MA, 01923. Specific written permission must be obtained for all other copying.

Printed in the United States of America.

Periodicals postage paid at New York, NY, and additional mailing offices. Postmaster: send address changes in the US, Canada, and Mexico to: AlEDAM: Artificial Intelligence for Engineering Design, Analysis and Manufacturing, Journals Department, Cambridge University Press, 110 Midland Avenue, Port Chester, NY $10573-4930$. 


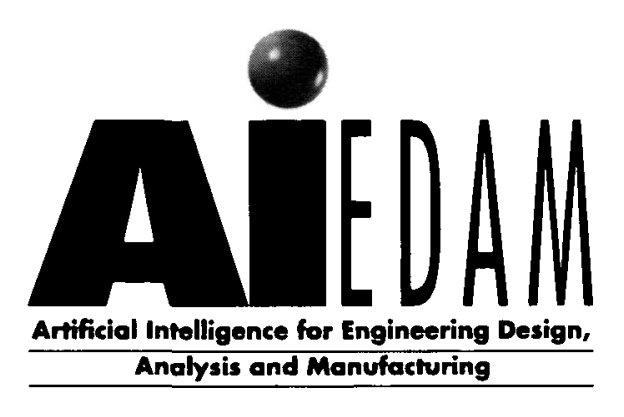

VOLUME 11

SEPTEMBER 1997

NUMBER 4

SPECIAL ISSUE

Geometric Representation and Reasoning in Design

\author{
Guest Editors
}

ROBERT WOODBURY

Carlos Damski 